\title{
Efecto antimicrobiano In vitro de propóleos argentinos, colombianos y cubano sobre Streptococcus mutans ATCC 25175
}

\author{
Zulma Moreno H. OD. ${ }_{\text {, }}$ Patricia Martínez A. OD. ${ }^{1}$, Judith Figueroa. MSc. ${ }^{2}$ \\ ${ }^{1}$ Universidad Nacional de Colombia Facultad de Odontología. Sede Bogotá. \\ ${ }^{2}$ Lic. Micr. MSc. Docente, Facultad de Medicina Veterinaria y de Zootecnia, Universidad Nacional de Colombia. Sede Bogotá.
}

Correspondencia: revistanova@unicolmayor.edu.co

Recibido: 9-05-2007 / Aceptado: 13-06-2007

\section{Resumen}

Se evaluó la actividad antimicrobiana de cuatro extractos de propóleos argentinos, cinco colombianos y uno cubano frente a Streptococcus mutans ATCC 25175. La actividad bactericida y bacteriostática fue medida por concentración mínima inhibitoria en un rango entre 0.02 y $15 \mathrm{mg} / \mathrm{ml}$. La totalidad de las muestras analizadas presentaron actividad contra Streptococcus mutans a concentraciones de 15 a $3.75 \mathrm{mg} / \mathrm{ml}$. Los propóleos que presentaron mayor efecto bactericida fueron el 2 y el 3 (muestras colombianas) luego de 48 horas de incubación. El mejor efecto bacteriostático lo presentó la muestra 2 (propóleo colombiano) a un periodo de incubación de 24 horas. E1 70\% de las muestras de propóleo incrementaron su actividad luego de un tiempo de incubación de 48 horas, en relación con el efecto detectado a las 24 horas. A mayor exposición de las bacterias al propóleo, las muestras colombianas mostraron un efecto superior, las argentinas un efecto moderado y las demás muestras (30\%), permanecieron estables.

Palabras claves: concentración mínima bactericida, concentración mínima bacteriostática, propóleo, Streptococcus mutans.

\begin{abstract}
It was evaluated the antimicrobial activity of four propolis extracts from Argentina, five from Colombia and one from Cuba, using Streptococcus mutans ATCC 25175. The samples were kept in a 96\% ethylic alcohol solution, remaining a concentration of $3 \%$. The bactericidal and bacteriostatic activity was measured by the minimun inhibitory concentration among a range of 0.02 and $15 \mathrm{mg} / \mathrm{ml}$. All of the analyzed samples showed activity against Streptococcus Mutans when they are used to concentrations 15 a $3.75 \mathrm{mg} / \mathrm{ml}$.

The propolis that presented the highest effect bactericidal was number 2 and 3 (sample from Colombia) after 48 hours of incubation. The highest effect bacteriostatic was presented by the sample 2 (propolis from Colombia) after 24 hours of incubation. $70 \%$ of the propóleo samples increased their activity after a time of incubation of 48 hours compare to the effect shown to the 24 hours.
\end{abstract}


All the Colombian samples showed a superior effect, when the bacteria were exposed to the propóleo for a longer period of time; in two of these cases until of five dilutions, samples 2 and 3 , this effect was presented in a moderate way, using the argentine samples 6 and 10 while the other samples (30\%) remained steady.

Keywords: minimun bactericidal concentration, minimun bacteriostatic concentration, propolis, Streptococcus mutans.

\section{Introducción}

El Streptococcus mutans es el principal microorganismo implicado en el desarrollo de la caries dental (1), afecta a un gran número de personas en nuestro país. El $95 \%$ de la población mayor de 20 años posee historia de caries, lo que convierte a esta patología en un problema de salud pública (2). La implementación de nuevos métodos para disminuir la prevalencia e incidencia de esta enfermedad son necesarias. El uso indiscriminado de antibióticos, ha generado resistencia bacteriana, por lo cual es preciso tener alternativas preventivas y terapéuticas, como los propóleos a los cuales no se les ha descrito resistencia alguna $(3,4)$.

En los últimos años se han realizado innumerables investigaciones acerca de productos provenientes de las abejas y sus potenciales beneficios para la salud humana, uno de estos productos es el propóleo, con utilidad en biología y medicina (4). Dobrowolski y colaboradores mencionan algunos de sus efectos como: actividad antiinflamatoria, bacteriostática, bactericida, cicatrizante, analgésica y anestésica (5). Es de resaltar que la presencia en el propóleo de compuestos con estas actividades, pueden variar de una región a otra, ya que su presencia se asocia en parte a las resinas que las abejas recogen de las plantas presentes en el entorno (4).

Este trabajo de investigación se enfoca a la actividad bactericida y bacteriostática de propóleos frente a un microorganismo de cavidad oral como el Streptococcus mutans. Según Hyun Koo y colaboradores, el propóleo inhibe la unión de este microorganismo a la superficie del esmalte, actuando sobre la enzima glucosiltransferasa que ha sido reconocida como un factor de virulencia en la patogenicidad de la caries dental $(6,7)$.

\section{Materiales y métodos}

Se partió de crioviales que contenían la cepa de referencia Streptococcus mutans ATCC 25175. Para la recuperación de la bacteria se empleó caldo y agar BHI (Infusión Cerebro Corazón) (8), con incubación a $37^{\circ} \mathrm{C}$ por 48 horas en condiciones microaerofílicas (9).

Extractos blandos de propóleo: se tomaron cuatro muestras de propóleo argentino, cinco colombianos y uno cubano, que habían sido obtenidos por extracción con alcohol etílico al 96\% (3). Para ajustarlos todos a la misma concentración, se tomó una submuestra de cada propóleo y se llevó a evaporación a $37^{\circ} \mathrm{C}$ por 24 horas, para la obtención del extracto blando. Posteriormente, se pesó el extracto obtenido y con base en este resultado se prepararon diluciones en alcohol etílico al 96\%, para así obtener una solución a concentración de 30mg/mL (3\%) (3).

La técnica empleada para hallar la Concentración Mínima Inhibitoria (CMI), fue la reportada por el equipo de Tolosa (10). Consiste en tomar 10 tubos de ensayo con $2 \mathrm{ml}$ de caldo BHI en cada uno; al primero de ellos se añade $2 \mathrm{ml}$ del extracto de propóleo y se realizan diluciones seriadas en base dos. De esta manera se consiguen diluciones entre 15 y $0.02 \mathrm{mg} / \mathrm{mL}$ de propóleo.

Posteriormente, se inoculó $0.1 \mathrm{~mL}$ de solución bacteriana a una escala de turbidez de Mc. Farland No. 3 equivalente a $9 \times 10^{8} \mathrm{UFC} / \mathrm{mL}$, para cada uno de los diez tubos. Para este estudio se incluyó un control con alcohol etílico al 96\%. Luego de este proceso, se incubó por 24 horas a $37^{\circ} \mathrm{C}$. Pasado este lapso de tiempo se sembró de cada tubo $100 \mu 1$. Con asa calibrada en Agar BHI y se llevó nuevamente a incubación bajo las mismas condiciones. Este proceso se repitió luego de 48 horas de exposición de la bacteria al propóleo. 


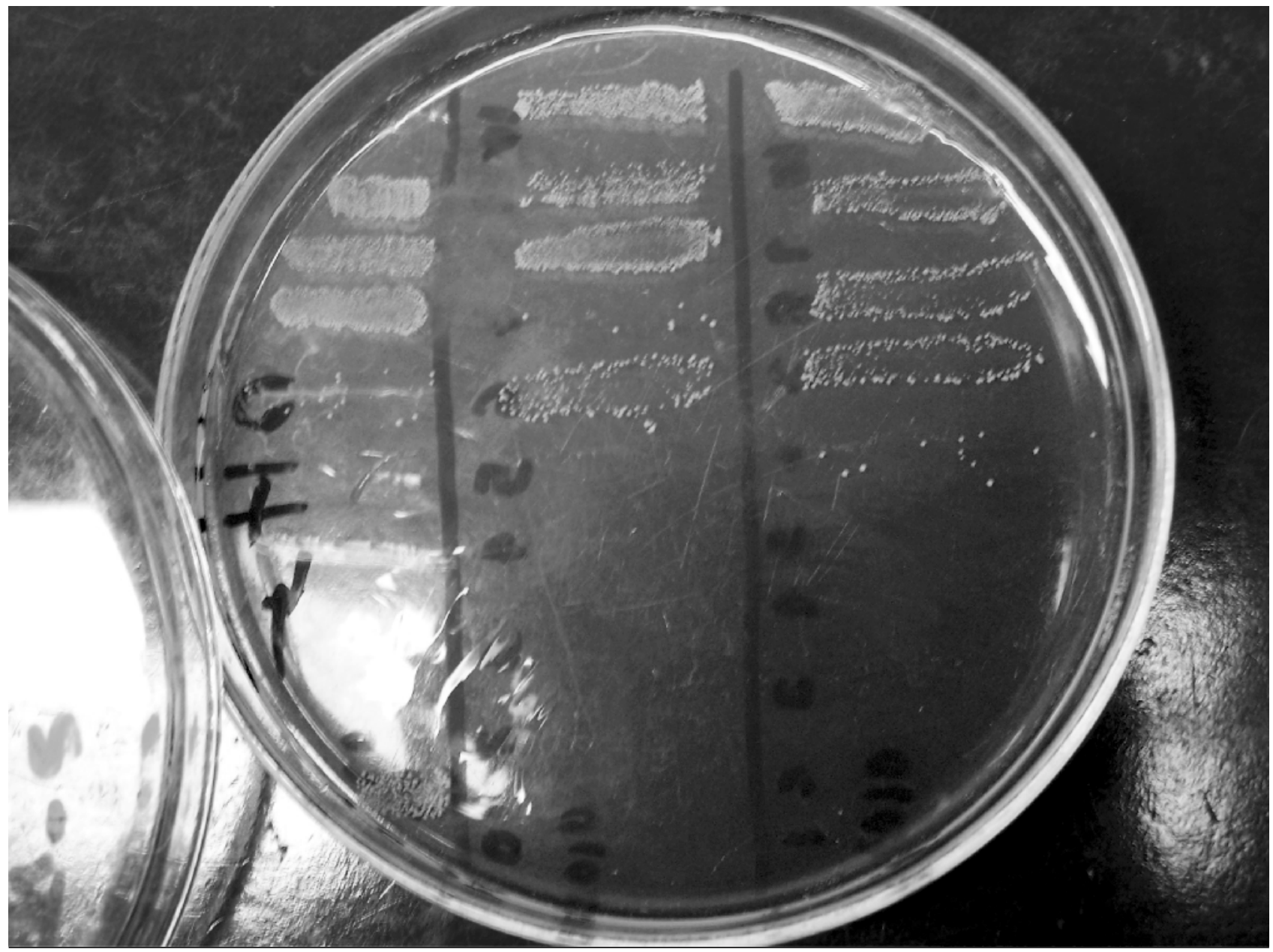

Figura 1. Lectura CMB CMB y CMBs en Agar BHI.

Las lecturas de concentración mínima bacteriostática (CMBs) se evaluaron por el grado de crecimiento o no de la bacteria luego de haber estado expuesta a la actividad de los distintos propóleos en un lapso de tiempo de 24 y 48 horas. La concentración mínima bactericida (CMB) se consideró como la dilución más alta en la cual no se presentó crecimiento bacteriano y la CMBs como la dilución más alta en la cual el crecimiento bacteriano fue mínimo (máximo 5 colonias), Figura 1.

\section{Resultados}

En la prueba de CMI, el alcohol mostró interferencia para la lectura en la concentración de $15 \mathrm{mg} / \mathrm{mL}$ de propóleo, pero no en diluciones más altas $(7,5$ a 0.02 $\mathrm{mg} / \mathrm{mL}$ ), por lo tanto no hubo interferencia con las lecturas de la prueba.
La totalidad de las muestras analizadas manifestaron actividad contra Streptococcus mutans cuando se emplean a concentraciones de 15 a $3.75 \mathrm{mg} / \mathrm{mL}$. Los propóleos estudiados poseen actividad bactericida y bacteriostática frente a la cepa de referencia Streptococcus mutans ATCC 25175. Los compuestos biológicamente activos del propóleo que determinan esta inhibición no fueron analizados en este estudio. El propóleo mostró actividades inhibitorias a concentraciones tan bajas como $0.02 \mathrm{mg} / \mathrm{mL}$, lo cual se observó en el caso de las muestras 2 y 3, propóleos colombianos, Tabla 1.

Los propóleos colombianos aumentaron la actividad bactericida a las 48 horas con respecto a la lectura de las 24 horas, pasando de 0.46 a $0.11 \mathrm{mg} / \mathrm{mL}$ para la muestra 1 , de 0.93 a $0.02 \mathrm{mg} / \mathrm{mL}$ para las muestras $2 \mathrm{y}$ 
3, de 7.5 a $0.46 \mathrm{mg} / \mathrm{mL}$ para la muestra 4 y de 3.75 a $0.93 \mathrm{mg} / \mathrm{ml}$ para la muestra 5. Dos de las muestras provenientes de Argentina mostraron un cambio en su actividad bactericida durante el paso de 24 a 48 horas, la muestra 6 de 0.46 a $0.23 \mathrm{mg} / \mathrm{mL}$ y la muestra $10 \mathrm{de}$
3.75 a $0.46 \mathrm{mg} / \mathrm{mL}$. Las demás muestras, incluyendo el propóleo cubano, no mostraron cambios en el tiempo. Las muestras 2, 3, 4, 5 y 10 evidenciaron efectos bacteriostáticos a las concentraciones estudiadas.

Tabla 1. Actividad bactericida y bacteriostática de propóleo de diferente origen frente a la cepa de referencia de S. mutans ATCC 25175.

\begin{tabular}{|c|c|c|c|c|c|c|c|c|c|c|c|c|}
\hline \multicolumn{13}{|l|}{ Origen del propóleo } \\
\hline & {$[\mathrm{mg} / \mathrm{mL}]$} & 15 & 7,5 & 3,75 & 1,87 & 0,93 & 0,46 & 0,23 & 0,11 & 0,05 & 0,02 & $t / h$ \\
\hline \multirow[t]{2}{*}{ Colombia } & 1 & - & - & - & - & - & - & + & + & + & + & 24 \\
\hline & & - & - & - & - & - & - & - & - & + & + & 48 \\
\hline \multirow[t]{2}{*}{ Colombia } & 2 & - & - & - & - & - & $b$ & $b$ & + & + & + & 24 \\
\hline & & - & - & - & - & - & - & - & - & - & - & 48 \\
\hline \multirow[t]{2}{*}{ Colombia } & 3 & - & - & - & - & - & $b$ & + & + & + & + & 24 \\
\hline & & - & - & - & - & - & - & - & - & - & - & 48 \\
\hline \multirow[t]{2}{*}{ Colombia } & 4 & - & - & $b$ & + & + & + & + & + & + & + & 24 \\
\hline & & - & - & - & - & - & - & $b$ & + & + & + & 48 \\
\hline \multirow[t]{2}{*}{ Colombia } & 5 & - & - & - & $b$ & + & + & + & + & + & + & 24 \\
\hline & & - & - & - & - & - & $b$ & $b$ & $b$ & + & + & 48 \\
\hline \multirow[t]{2}{*}{ Mendoza (Arg) } & 6 & - & - & - & - & - & - & + & + & + & + & 24 \\
\hline & & - & - & - & - & - & - & - & + & + & + & 48 \\
\hline \multirow[t]{2}{*}{ Buenos Aires (Arg) } & 7 & - & - & - & - & - & - & - & + & + & + & 24 \\
\hline & & - & - & - & - & - & - & - & + & + & + & 48 \\
\hline \multirow[t]{2}{*}{ Cubano } & 8 & - & - & - & - & - & - & + & + & + & + & 24 \\
\hline & & - & - & - & - & - & - & + & + & + & + & 48 \\
\hline \multirow[t]{2}{*}{ Mendoza (Arg) } & 9 & - & - & - & - & - & - & + & + & + & + & 24 \\
\hline & & - & - & - & - & - & - & + & + & + & + & 48 \\
\hline \multirow[t]{2}{*}{ Mendoza (Arg) } & 10 & - & - & - & $b$ & $b$ & $b$ & $b$ & + & + & + & 24 \\
\hline & & - & - & - & - & - & - & + & + & + & + & 48 \\
\hline \multirow[t]{2}{*}{ Control } & & - & + & + & + & + & + & + & + & + & + & 24 \\
\hline & & - & + & + & + & + & + & + & + & + & + & 48 \\
\hline
\end{tabular}

Sin crecimiento (-) Crecimiento (+) Bacteriostático (b) Tiempo en horas (t/h)

Los valores límite bacteriostático y bactericidas para cada propóleo se muestran en la Tabla 2. Los promedios de actividad bacteriostática correspondieron a concentraciones de propóleo de $1,141 \mathrm{mg} / \mathrm{mL}$ y de actividad bactericida de $1,893 \mathrm{mg} / \mathrm{mL}$.

\section{Discusión}

Para todas las muestras colombianas se evidenció un efecto superior, a mayor exposición de las bacterias al propóleo, para las muestras 2 y 3 hasta de cinco diluciones, las cuales superaron su CMB inicial, pasando de $0.93 \mathrm{a}=0.02 \mathrm{mg} / \mathrm{mL}$ en ambos casos; éste efecto sólo se observó en dos de las muestras argentinas, pero con una diferencia menor, la muestra 6 aumentó su CMB de 0.43 a $0.23 \mathrm{mg} / \mathrm{mL}$ y la muestra 10 de 3.75 a $0.46 \mathrm{mg} /$ $\mathrm{mL}$. Los propóleos restantes, incluyendo la muestra de origen cubano, se mantuvieron estables en el tiempo.

Dos muestras colombianas mostraron poca acción luego de 24 horas de incubación, comparándolas con las demás, la actividad bactericida y bacteriostática se evidenció a concentración de $7.5 \mathrm{mg} / \mathrm{mL}$ (CMB) y 3.75 $\mathrm{mg} / \mathrm{mL}$ (CMBs) para la muestra 4 y para la muestra 5 de $3.75 \mathrm{mg} / \mathrm{mL}$ (CMB) y $1.87 \mathrm{mg} / \mathrm{mL}$ (CMBs). Estos resultados estuvieron por debajo del promedio de los propóleos analizados. Las muestras 2 y 3 , de origen colombiano, fueron las que presentaron un mejor compor- 
Tabla 2. Valores en $\mathrm{mg} / \mathrm{mL}$ para CMB y CMBs por muestra frente a S. mutans ATCC 25175

\begin{tabular}{|c|c|c|c|c|}
\hline \multirow[t]{2}{*}{ Origen } & \multirow{2}{*}{$\begin{array}{l}\text { No. de la } \\
\text { muestra }\end{array}$} & \multirow[t]{2}{*}{$\mathrm{t} / \mathrm{h}$ de lectura } & \multicolumn{2}{|c|}{$\begin{array}{c}\text { Acción del propóleo en } \mathrm{mg} / \mathrm{ml} \text { sobre } S \\
\text { mutans }\end{array}$} \\
\hline & & & CMB & CMBs \\
\hline \multirow[t]{2}{*}{ Colombia } & 1 & 24 & 0,46 & NP \\
\hline & & 48 & 0,11 & NP \\
\hline \multirow[t]{2}{*}{ Colombia } & 2 & 24 & 0,93 & $0,46-0,23$ \\
\hline & & 48 & $\geq 0,02$ & NP \\
\hline \multirow[t]{2}{*}{ Colombia } & 3 & 24 & 0,93 & 0,46 \\
\hline & & 48 & $\geq 0,02$ & NP \\
\hline \multirow[t]{2}{*}{ Colombia } & 4 & 24 & 7,5 & 3,75 \\
\hline & & 48 & 0,46 & 0,23 \\
\hline \multirow[t]{2}{*}{ Colombia } & 5 & 24 & 3,75 & 1,87 \\
\hline & & 48 & 0,93 & $0,46-0,11$ \\
\hline \multirow[t]{2}{*}{ Mendoza (Arg) } & 6 & 24 & 0,46 & NP \\
\hline & & 48 & 0,23 & NP \\
\hline \multirow{2}{*}{ Buenos Aires (Arg) } & 7 & 24 & 0,23 & NP \\
\hline & & 48 & 0,23 & NP \\
\hline \multirow[t]{2}{*}{ Cuba } & 8 & 24 & 0,46 & NP \\
\hline & & 48 & 0,46 & NP \\
\hline \multirow[t]{2}{*}{ Mendoza (Arg) } & 9 & 24 & 0,46 & NP \\
\hline & & 48 & 0,46 & NP \\
\hline \multirow[t]{2}{*}{ Mendoza (Arg) } & 10 & 24 & 3,75 & $1,87-0,23$ \\
\hline & & 48 & 0,46 & NP \\
\hline
\end{tabular}

Tiempo en horas (t/h) Concentración mínima bactericida (CMB) Concentración mínima bacteriostática (CMBs) No presento (NP)

tamiento, ya que en ambas se detectó un efecto bactericida a una baja concentración $=0.02 \mathrm{mg} / \mathrm{ml}$ luego de 48 horas de incubación.

El tiempo de exposición de las bacterias al propóleo es una variable importante en la evaluación de la actividad frente a $S$. mutans. Al evaluar a 24 y 48 horas, mejora la capacidad para destruir el microorganismo, efecto evidente en la actividad de las muestras 1 a 6 y 10, que después de trascurridas 48 horas mejoraron su actividad bacteriostática y bactericida, Figuras 2 y 3 . El $100 \%$ de las muestras de propóleos colombianos y al $50 \%$ de los argentinos tuvieron este efecto.

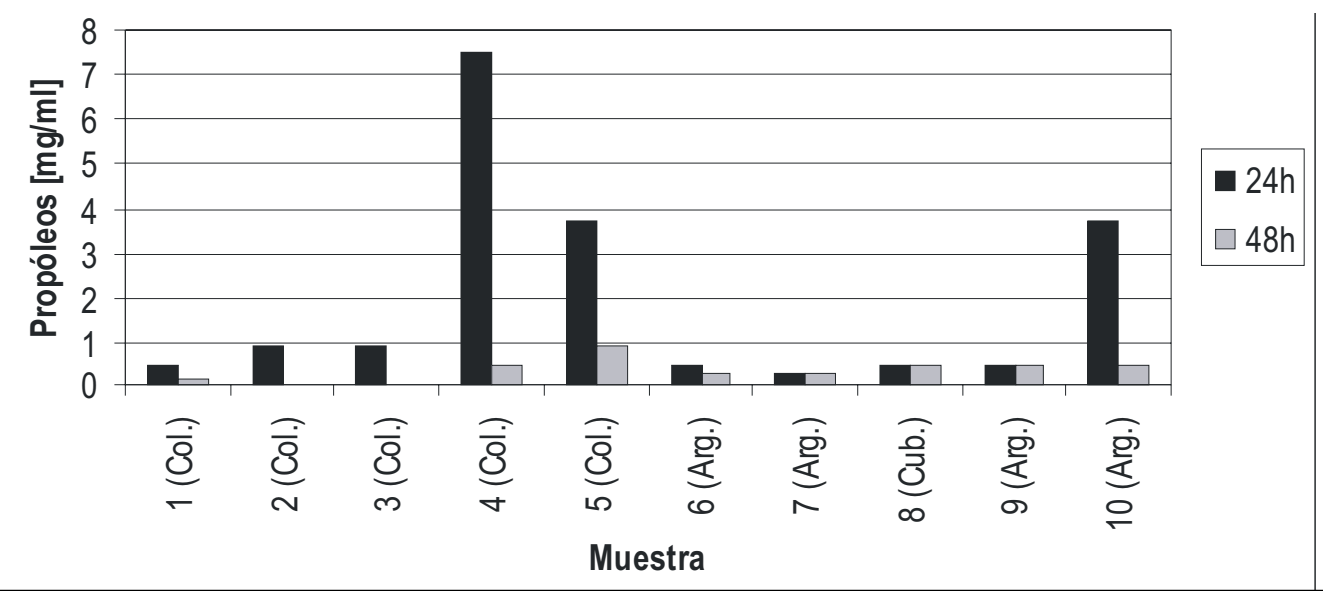

Figura 2. CMB de propóleos sobre S. mutans luego de 24 y 48 horas de exposición. 
Figura 3. CMBs de propóleo sobre S. mutans ATCC 25175 luego de 24 y 48 horas de exposición.

Las muestras de propóleo 7, 8 y 9 no presentaron variación en las lecturas realizadas durante las 24 y 48 horas, ya que su CMB en ambos periodos de tiempo permaneció estable, Figuras 2 y 3.

Todos los propóleos analizados mostraron algún grado de actividad antimicrobiana sobre Streptococcus mutans. Las concentraciones empleadas en el estudio correspondieron a las mismas utilizadas en los estándares para pruebas in vitro, de antibióticos comerciales. Esto

4 5 demuestra el alto potencial de uso de los propóleos en el humano, dado que no ha sido descrito resistencias bacterianas a estos compuestos naturales de las abejas. Los hallazgos de estudio permiten plantear el uso de propóleos activos a streptococcus mutans en la prevención de la caries dental, teniendo en cuenta que

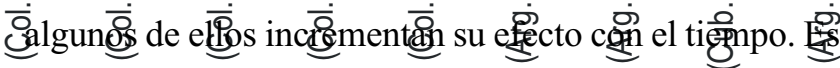
importănte côntinuat los es̊tudios sobre propółeos y $\mathrm{Su}$ uso potencial en la prevencibustratamiento de patologías de cavidad oral.

\section{Agradecimientos}

A la Facultad de odontología de la Universidad Nacional, en particular a Rosalba Medina y a Sonia J. Gutiérrez por el suministro de la cepa de Streptococcus mutans ATCC 25175. A Telmo Martínez Anzola propietario del Apiario los Cítricos por el suministro de propóleos Colombianos. A Julio Cesar Díaz MD y Juan José Gutiérrez por facilitar los propóleos argentinos y
Cubano. A la División de Investigación de la Universidad Nacional Sede Bogotá (DIB) por el apoyo financiero.

\section{NOVA}

\section{Referencias}

1. Tanzer J, Livingston J, Thompson A. The Microbiology of Primary Dental Caries in Humans. J Dent Educ. 2001;65:1028-1037.

2. Ministerio de Salud. Galviz RV. III Estudio Nacional de Salud Bucal - ENSAB III, II Estudio Nacional de Factores de Riesgo de Enfermedades Crónicas. ENFRECII; Tomo VII Estudio Nacional de Salud Bucal, Colombia 1999.

3. Martínez T, Figueroa J, Martinez N. Actividad antimicrobiana de muestras de propóleo Colombiano. Espectro antimicrobiano del propóleo proveniente de apiarios de la zona norte del Valle del Cauca y Sur del Quindío. En Trabajo de graf4 $h_{F}$ acultad de Medicina Veterinaria y de Zootecnia Univers dad Nacional de Colombia, 2003.

4. Farre R, Erasquet I, Sánchez A. El propolis y la salud. Ars Pharama. 2004;45:21-43.

Dobrowolski J, Vohora S, Sharma K, Shah S, Naqvi S, Dandiya P. Antibacterial, antifungal, antiamoebic, antiinflammatory - and antipyretic studies on propolis bee products. J

언 Ethnopharnacol.1991;35:77-82.

$6 . \$$ Koo H, Rosalen P, Cury J, Park Y, Bowen W. Effects of

으 compounds found in propolis on Streptococcus mutans growth and on glucosyltransferase activity. Antimicrob Agents Chemother. 2002;46:1302-1309.

7. Duarte S. Rosalen P, Hayacibara M, Cury J, Bowen W, Marquis R, Rehder V, Sartoratto A, Ikegaki M, Koo H. The influence of a novel propolis on mutans streptococci biofilms and caries development in rats. Arch Oral Biol. 2006;51:15-22.

8. Pinto M, Rodríguez MC, Median R. Prueba "in vitro" del líquido de la cáscara de la nuez de marañon (Anacardium occidentale) en el Streptococcus mutans. Trabajo de Pregrado Facultad de Odontología Bogotá D.C. 1993, Distinción meritoria. Mención de honor XI Encuentro de Investigación en Odontología ACFO Medellín 2000.

9. Tanzer JM, Börjesson AC, Laskowski L, Testa M. Glucosesucrose-potassium tellurite-bacitracin agar, an alternative to mitis salivarius-bacitracin agar for enumeration of Streptococcus mutans. J Clin Microbiol. 1984;20:653-659.

10. Tolosa L, Cañizares E. Obtención, caracterización y evaluación de la actividad antimicrobiana de extractos de propóleos de Campeche. Ars Pharmac. 2002;43:187-204. 